\title{
FORMA Y MEDIDA EN LOS VERSOS GRECO-LATINOS LA GÉNESIS DEL SISTEMA DE NIVELES *
}

J. LUQUE MORENO Univ. de Granada

Reflexiones sobre la génesis del sistema del lenguaje versificado, con especial atención al origen tanto de las formas métricas como de la medida de dichas formas.

Palabras clave: Origen versos, origen teoría métrica.

\section{Presentación.}

En dos ocasiones me he ocupado de diversas cuestiones y aspectos implícitos en la distinción entre sistema y realización en el lenguaje versificado. En una de ellas ${ }^{1}$ ponía el acento en los distintos planos o niveles que procede distinguir en el análisis de algo tan complejo como es la expresión lingüística en verso. En la segunda ${ }^{2}$ precisaba algunas facetas de lo ya expuesto, insistiendo más en las raíces que todos estos modernos enfoques de la cuestión parecen tener en la teoría antigua, más en concreto, en la antigua doctrina rítmica.

Evidentemente cuanto allí quedó dicho no es, ni mucho menos, todo lo que hay que decir acerca de este asunto, sobre todo, moviéndonos como nos movíamos en el plano de las meras sugerencias y dentro de los límites materiales de una colaboración a un volumen colectivo y de un artículo de revista. Como ya quedó allí sugerido, otras muchas facetas de tan fecunda cues-

* Este trabajo se enmarca en el proyecto de investigación BFF 2001-3152.

1 Luque 1984.

2 Luque $1984 b$. pp. $231-256$ 
tión quedaban pendientes de tratamiento, a la espera de una ocasión oportuna y un marco adecuado en que desarrollarlas. A lo largo de los años que desde la publicación de aquellos trabajos han transcurrido he tenido ocasión de comprobar la efectividad de aquel sistema de niveles de análisis en el estudio de los versos latinos, tanto en un planteamiento sincrónico del sistema métrico, sus principios, sus formas, sus unidades, etc., como en el estudio diacrónico de las formas versificatorias latinas hasta llegar a la versificación acentual e incluso, si es el caso, a la romance.

Hoy vuelvo sobre el tema, con la intención de realizar algunas precisiones a aquel sistema de niveles, y lo hago desde un enfoque diacrónico o, más en concreto, diacrónico retrospectivo, tratando de apuntar nada menos que a lo que pudo ser la génesis, la constitución de dicho sistema de niveles.

Se trata, ni más ni menos, de volver, ahora desde esta perspectiva, sobre una cuestión medular en la métrica antigua, una cuestión planteada desde hace milenios: el problema de la naturaleza y el origen de un sistema tan rico y complejo como el de la versificación greco-latina y la no menos ardua problemática de la configuración de los sistemas de doctrina que desde hace veintiséis siglos se han perfilado en torno a él y, por supuesto, de la relación mutua entre aquellas formas de versificación y estos sistemas de doctrina.

Dos realidades que conviene dejar bien distinguidas desde el principio: el verso y la métrica, la realidad de los hechos y los sistemas doctrinales que tratan de explicarlos. Dos realidades distintas, pero evidentemente interrelacionadas y más de una vez, sobre todo para quienes se han enfrentado a los hechos con siglos de distancia, mutuamente condicionadas. Bien sabido es que a veces una interpretación de la realidad se consolida y llega a adquirir un peso suficiente como para ser confundida con la propia realidad, constituyendo una especie de segunda naturaleza; es lo que nos ocurre, por ejemplo, con el metro, una unidad convencional de medida de longitud tan arraigada en nuestra cultura que ha cobrado entre nosotros carta de naturaleza y condiciona nuestra propia percepción de la longitud. Y otro tanto cabría decir de la hora, como medida convencional del tiempo. O también probablemente del sistema tonal en la música occidental ${ }^{3}$.

\footnotetext{
3 A propósito de lo cual escribía Schönberg: «hay que tener en cuenta que nuestro oído hoy no reacciona simplemente a las condiciones naturales, sino que está condicionado por ese sistema que con el tiempo ha llegado a ser una segunda naturaleza. Apenas podemos hoy gradualmente evadirnos de esa cultura, de ese producto artístico, y la reflexión sobre la naturaleza puede tener un valor teorético sin por ello producir inmediatamente frutos artísticos. Sin duda
} 
Petulante arrogancia sería por mi parte pretender entrar en este campo con el ánimo de quien trae en las manos la panacea para todos los males y la solución para todos los problemas; a poco que se conozcan éstos y la compleja historia de las múltiples soluciones que se les han propuesto se tiene enseguida conciencia de que difícilmente se puede hacer brillar sobre ellos la luz de una verdad absoluta y definitiva.

Bien es verdad que el que hoy aborda estas cuestiones juega ya no sólo con la ventaja de muchos siglos de tradición doctrinal, sino, sobre todo, con la de más de dos centurias de eminentes estudios sobre el problema y, más aún, con la ventaja añadida del aire fresco que por todo este paisaje han hecho correr desde el siglo XIX los avances de un comparativismo rigurosamente positivista y los nuevos enfoques científicos de los últimos decenios, que han cuajado en una doctrina firme sobre la versificación indoeuropea.

Aun así, no acudo aquí tanto con la certeza de poder aportar soluciones cuanto con el ánimo de sistematizar problemas. Si tal sistematización supone un nuevo paso hacia las anheladas soluciones, podré dar por bien cumplida mi tarea.

De sistema se trata; esto ha de tenerse bien en cuenta. Los versos, como toda la lengua, son un sistema. Y su estudio ha de plantearse necesariamente sistemático, estructural, si se prefiere. Sistemático en el más estricto sentido de la palabra, es decir, abordando, de un lado, la realidad en toda la amplitud y complejidad de su sistema y limitándose, de otro, a la estricta realidad del objeto estudiado. De cualquier tipo de desajuste o desvío en este planteamiento viene, sin duda, una buena parte de tantos males y problemas como han aquejado siempre al estudio de la métrica y de la versificación. Verdad es que dichos males provienen también (y no sólo ahora, sino desde que la métrica empezó a conformarse como tal disciplina en las mesas de trabajo de los filólogos helenísticos) del propio objeto de estudio, complejo siempre y, para nosotros, excesivamente avaro en materiales muchas veces. Pero más de un escollo se habría sorteado si un objeto de semejante dificultad hubiese sido siempre abordado en su marco justo y en las condiciones de sistematicidad antes aludidas; si no se hubiesen planteado aspectos parciales con desatención del resto de las facetas; si no se hubieran abordado los

un día volverá a recorrerse este camino, robando nuevos secretos a la naturaleza. Sin duda también las nuevas conquistas se estilizarán en otro sistema, pero primero habrá que quitar del camino el viejo sistema»: Schönberg 1974, p. 49. 
hechos desde perspectivas ajenas a la entidad esencial de los mismos; si no se hubieran adoptado con un apriorismo poco científico posturas sistematicistas o antisistemáticas que sacrifican parte de la realidad en aras del mantenimiento de un sistema teórico que parece dar razón de la otra parte; si no se hubieran confundido y mezclado indiscriminadamente los distintos planos o niveles en que, según hoy se acepta, se mueve la compleja realidad del lenguaje versificado.

Partiendo, pues, como hipótesis de trabajo de mi personal visión del sistema de funcionamiento y análisis de los versos (de un lado, la "Forma rítmica", la "Forma métrica" y el "Esquema", como distintos grados de generalidad y de abstracción en el sistema; de otro, la "Composición" y la "Ejecución", como dos planos distintos en la realización de aquel sistema), voy a afrontar una vez más dicha estructura de niveles, ahora desde una perspectiva histórico-genética, más en concreto, desde el doble punto de vista del origen de las propias formas y del establecimiento de una teorización sobre dichas formas.

\section{Ante enim carmen quam obseruatio carminis}

Bien claro ha de quedar desde el comienzo, como primera premisa, el que primero fueron los versos y luego la métrica. "Antes, en efecto, surgió el carmen que la observación del carmen", afirmaba ya Quintiliano ${ }^{4}$, expresando así un principio que tomaría luego Wilamowitz como uno de los puntos de partida de su Griechische Verskunst: «Der Vers ist alter als seine Messung» ${ }^{5}$. El verso, pues, es anterior a su propia medida. La métrica, el metro, no es otra cosa que medida y, como tal, teorización, interpretación de una realidad previa, la realidad que se mide.

La distinción es clara, si bien históricamente, en la contingencia histórica, y más en este caso en que lo que se mide es sonido que se realiza en el tiempo (es decir, algo motriz y temporal), la medida va íntimamente unida a la propia percepción de lo medido (el ritmo es algo a la vez producido y percibido) y puede empezar desde muy pronto a condicionar en cierto modo la propia entidad de lo medido. Pero no es exactamente en este punto de la percepción del ritmo (y de si preferentemente se produce o se percibe) donde pretendo moverme, sino en el de que la constitución de una doctrina métrica propia-

4 Ante enim carmen ortum est quam obseruatio carminis: IX 4, 115. 1921, p. 25. 
mente dicha e incluso la configuración de una teoría rítmico-métrica en el sentido más amplio, musical, del término, es algo históricamente posterior a la existencia de una realidad, de unas danzas, de unos cantos, de unos módulos de recitado, es decir, de unas formas; y dichas formas, al menos aquéllas que se pueden considerar más antiguas u originarias, son anteriores a las correspondientes medidas, a la métrica.

En este sentido se establece ya un parámetro necesario para la valoración y el estudio de los hechos: la necesidad de distinguir, dentro de lo posible, entre formas anteriores a la métrica y formas posteriores a la métrica y, por tanto, susceptibles, en principio, de haber sufrido en su constitución el condicionamiento de la propia medida, del propio sistema teórico ya establecido.

Por los datos históricos a nuestro alcance (datos tanto en lo referente a los propios versos, como en lo que respecta a la constitución de los sistemas teóricos de rítmica y de métrica) podemos aceptar sin graves riesgos de error que esos materiales "premétricos" hay que buscarlos en todo caso entre aquéllos que parecen remontables a una etapa preliteraria o, si se prefiere, a una etapa pregráfica, de literatura exclusivamente oral. La dificultad radica, lógicamente, en que dicho material prehistórico, preliterario, premétrico, sólo nos es accesible en cuanto que nos permiten reconstruirlo los materiales que, desarrollados a partir de él, se han conservado en época histórica.

\section{El origen de las formas métricas}

El deseo de reconstruir esa prehistoria ha estado siempre presente, de forma más o menos explícita, en los estudios de métrica. Desde sus primeros pasos la métrica se ha planteado, de un modo u otro, la cuestión del origen, de la génesis de todas aquellas formas que estudiaba.

No otra cosa hacían los metricólogos alejandrinos desde sus teorías sobre

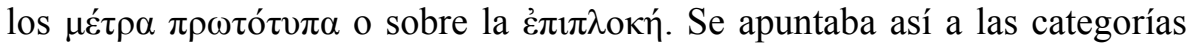
generales y primarias; pero se trataba de reconstruir ese pasado y ese origen a partir del sistema teórico posterior, a partir de y en función de unas "medidas" y de unas categorías rítmicas, lógicamente, posteriores a la propia realidad cuyos orígenes se pretendía alcanzar.

Algo similar hacían los seguidores de la otra corriente o sistema métrico antiguo, el "pergameno" o "varroniano", que, puede que como una desviación o incluso degradación del sistema alejandrino y dando cabida en sus planteamientos a principios y factores histórico-literarios, interpretaba todas 
las formas versificatorias como derivadas del hexámetro dactílico y del trímetro yámbico, los cuales, a su vez, remontaban a un ancestro común, cuya génesis trascendía ya las fronteras de lo histórico y se instalaba en lo mítico.

En la métrica moderna, casi desde sus primeros pasos, ha seguido abierta la cuestión del origen de las formas métricas: a todo lo largo del siglo XIX y a comienzos del XX se constata, desde una actitud romántica y una mentalidad historicista, una búsqueda incesante, y casi se podría decir que apasionada, del verso original, del Urvers. Para este verso primigenio, célula generadora de todas las formas posteriores, se hicieron una y otra vez propuestas, pero siempre desde la perspectiva "aposteriorística" del sistema teórico: como en la métrica antigua, se partía del propio sistema teórico, es decir, de la interpretación posterior, de "la medida", para llegar a "lo medido", a la realidad previa a dicha medida y a dicha interpretación.

Los estudios de Meillet dieron un giro definitivo en este campo y abrieron la puerta a planteamientos más positivos y objetivos, que se propusieron centrarse en la constatación de los datos que ofrece la realidad y tratar de analizarlos sin los prejuicios de ningún sistema teórico previo; por esa vía han discurrido luego las propuestas de Jacobson, de Watkins, de Cole, de Pighi, de West, de Nagy, etc.

Como resultado de todos estos estudios llevados a cabo por la senda del comparativismo positivista se reconoce hoy con fundamento la existencia ya en tiempos muy antiguos en la comunidad lingüística indoeuropea de una lengua poética ${ }^{6}$ y de una versificación con unas catacterísticas determinadas. Poniéndolas en relación con las de otros pueblos o culturas, se han reconocido en el establecimiento de dicha versificación unas fases de desarrollo coherentes: desde la simple repetición de frases (frases-verso) no isosilábicas, a la fijación de la longitud (número de sílabas) de dichas frases, a la regulación de las cadencias y a la posterior regulación retrógrada del resto del verso, a partir de la cadencia hasta llegar a conformar un esquema silábicocuantitativo fijo.

Junto a dichos principios rítmicos generales, se han reconocido como comunes a estos pueblos indoeuropeos, y por ende remontables a fases muy antiguas, unos cola típicos originarios, con unas dimensiones y características definidas. Cola que posteriormente, y ya en el plano de los desarrollos más o menos locales de las distintas ramas de la familia indoeuropea, fueron

$6 \quad$ West, 1973b, p. 179. 
germen de nuevas formas versuales a base de procedimientos bien reconocidos, como la yuxtaposición, la ampliación por detrás o por delante y la expansión interna. Buen ejemplo de todo este proceso de diversificación local de aquella herencia indoeuropea lo dan las tres tradiciones versificatorias griegas: la eolia, la jonia y la doria. Cola y formas versuales que, por otro lado, muestran ya desde el principio, en toda la comunidad indoeuropea, unas tendencias claras en lo que se refiere a su empleo o funcionamiento en la composición poética: empleos estíquicos, modelos concretos de agrupación estrófica, etc.

Simultáneos y paralelos a estos avances en el conocimiento de la primitiva versificación indoeuropea por el camino del comparativismo han sido los logros, no menos importantes y no menos decisivos para la cuestión que aquí nos ocupa, en el estudio de la dicción formular como procedimiento aún vivo en los estadios más antiguos de la versificación griega que conocemos. Todos estos estudios, encabezados por Parry y sus discípulos y con recientes aportaciones significativas como las de Nagy, han apuntado siempre a la misma diana a la que nosotros apuntamos aquí y ahora, es decir, al paso desde el lenguaje natural al literario, de la frase al verso, de las unidades rítmico-lingüísticas "naturales" (la sílaba, la palabra, la frase) a las unidades rítmico-lingüísticas "artificiales"; en una palabra, desde la "fórmula" a la "forma métrica".

\section{La génesis del sistema de niveles}

Pasemos, pues, a reconsiderar desde este panorama, desde este estado de la cuestión, todo el sistema de niveles que desde hace tiempo venimos reconociendo dentro del lenguaje versificado y tratemos de ver, de un lado, qué se puede aportar desde este método de análisis a dichos planteamientos $\mathrm{y}$, de otro lado, qué nos dicen tales planteamientos métricos actuales para nuestra estructura de niveles, en concreto, para su génesis y constitución.

\subsection{De la "fórmula" a la "forma métrica".}

Evidentemente, el punto de partida es el lenguaje o, incluso yendo más allá, la voz humana. In principio erat uerbum, o sea, in principio erat uox. Lo cual no es otra cosa que decir in principio erat rhythmus: la uox en tanto que sonus es temporal, motriz y, por ende, rítmica, ya que es un proceso sonoro discontinuo. 
Esa uox humana es el principio, la clave, el punto de apoyo y de arranque tanto del sistema lingüístico como del sistema musical. Me refiero a la que los antiguos denominaban uox articulata, la analizada y analizable, y, en consecuencia, útil para la comunicación; claramente distinguida de la uox confusa. Ambos sistemas, el lingüístico y el musical, se basan en la uox, en unos materiales sonoros producidos por la laringe humana.

El lenguaje, en cuanto que sustentado sobre un material sonoro, es necesariamente temporal y lineal; $y$, en cuanto que proceso sonoro discontinuo, se halla articulado en una serie de unidades de producción, una serie de unidades rítmicas "naturales" o "primarias" como la sílaba o la frase o, como en el caso de nuestras lenguas, la palabra.

Son esas unidades rítmicas "primarias" naturales la base de cualesquiera otras unidades rítmicas "secundarias" o "artificiales; ellas son el punto de partida de donde en último término arranca cualquier reelaboración rítmica con fines "poéticos" o artísticos y, en definitiva, todo el proceso de la versificación. Véanse al respecto estas palabras de Cicerón:

nihil est enim tam tenerum neque tam flexibile neque quod tam facile sequatur quocumque ducas quam oratio. Ex hac uersus, ex hac eadem dispares numeri conficiuntur; ex hac haec etiam soluta uariis modis multorumque generum oratio; non enim sunt alia sermonis, alia contentionis uerba, neque ex alio genere ad usum cotidianum, alio ad scaenam pompamque sumuntur; sed ea nos cum iacentia sustulimus e medio, sicut mollissimam ceram ad nostrum arbitrium formamus et fingimus. ${ }^{7}$

La configuración de cualquier sistema versificatorio, como es bien sabido, no hay que verla de otro modo que como un proceso de estereotipación o "estilización". estructura y sus posibilidades, se fijan las denominadas "fórmulas", que son el primer paso en este camino. Una fórmula es un segmento de cadena hablada con una forma y un contenido, segmento que ha quedado potenciado en virtud de circunstancias varias que lo han hecho especialmente llamativo, es decir, han hecho que en él se concentre la atención; en tal segmento está mostrando el lenguaje su capacidad de atraer sobre sí mismo la atención de hablantes y oyentes, o sea, su función poética,

Sin duda alguna, este proceso desde la lengua normal a la forma métrica no es otro que el proceso por el que surge el lenguaje literario, el lenguaje

7 De or. III 45, 177.

8 Abercrombie 1965, p. 16; De Groot 1968, p. 536; Allen 1973, p. 103: «Poetic language may be considered in general as stylization of ordinary language». 
poético. Desde la lengua coloquial a la poética o literaria se va pasando por esas etapas intermedias de fijación y estereotipación, es decir, por el estadio de las fórmulas, que no es otro que el del carmen, o sea, el del lenguaje marcado (¿cortado [carmen < carpo], organizado en trozos?), que llama así la atención sobre sí mismo. De ese carmen, en cuanto que "habla marcada" frente al habla normal, como "fórmula eficaz", germen del canto, de la danza, de la música instrumental, del verso, e incluso de la prosa artística, ya me he ocupado en otra ocasión ${ }^{9}$, atendiendo a la vez tanto a las modernas concepciones como a los antiguos puntos de vista al respecto.

Y debajo de dicha "habla marcada" subyace un proceso de fijación y segmentación que se produce de acuerdo con una serie de factores, como son unos condicionamientos psicológicos o antropológicos, unos principios rítmicos básicos y, por supuesto, la propia naturaleza de la lengua.

Entre los condicionamientos psicológicos cabría mencionar, de un lado, el hecho de que unas necesidades vitales de especial importancia (la caza, por ejemplo) o unas vivencias especialmente intensas (como la muerte, la guerra, el amor) hacen que se graben en la mente unas expresiones lingüísticas relacionadas con ellas; y esa especial atención lleva a la repetición ${ }^{10}$, lo cual es ya en sí un principio rudimentario de retorno rítmico, de verso, en el más estricto sentido del término. De otro lado, no hay que olvidar la realidad psicológica de que la mente humana concentra una especial atención en los finales de frase; algo que sin duda está en la base de que sea en esos finales donde antes o con mayor fuerza se han empezado a consolidar unos patrones formales fijos, unas cadencias.

Entre los principios rítmicos hay que recordar que los ritmos básicos se

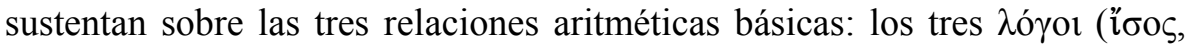

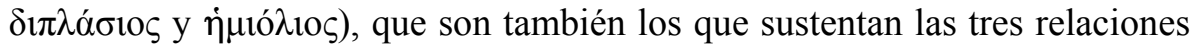
harmónicas fundamentales: el unísono, la octava y la quinta. Estos principios están sin duda en la base de la fijación de fórmulas rítmicas, cuyos elementos se relacionan "rítmicamente" entre sí según uno de estos $\lambda$ ó

$Y$, en lo que se refiere a la lengua, huelga decir que la fijación de esas

$9 \quad$ Luque 1998.

10 «Paleolitical man already had musical instruments and dancing. His musical phrases and his dance movements are likely to have been repetitive, and the same will have been true of his singing, not only because of its connection with the dance but because one of the principal springs of song is obsession with a given idea. Many illustrations of this may be found in C.M.Bowra's Primitive Song (1963)»: West 1982, p. 1. 
fórmulas y, en su caso, de las formas rítmico-métricas se ha hecho siempre, por supuesto, de acuerdo con la naturaleza de dicha lengua, de acuerdo, sobre todo, con sus unidades rítmicas naturales y, en último término, con su estructura prosódica, que, al fin y al cabo, es la que ofrece los materiales sobre los que dichas formas se van a sustentar.

Así, pues, a partir de las fórmulas y en virtud de su capacidad de transformación, de variar alguno de sus componentes sin alterar su estructura rítmica, se pueden llegar a constituir las formas métricas o rítmico-métricas: podremos decir que una forma está consolidada, que ha concluido el proceso de estereotipación, cuando en la conciencia colectiva de la comunidad hablante haya quedado fijado y grabado el patrón rítmico de una primitiva fórmula, desligado ya de las palabras concretas de donde se originó y dispuesto para ser cumplimentado o "realizado" a base de cualesquiera otras. Podríamos imaginar a este propósito algo así como lo siguiente:

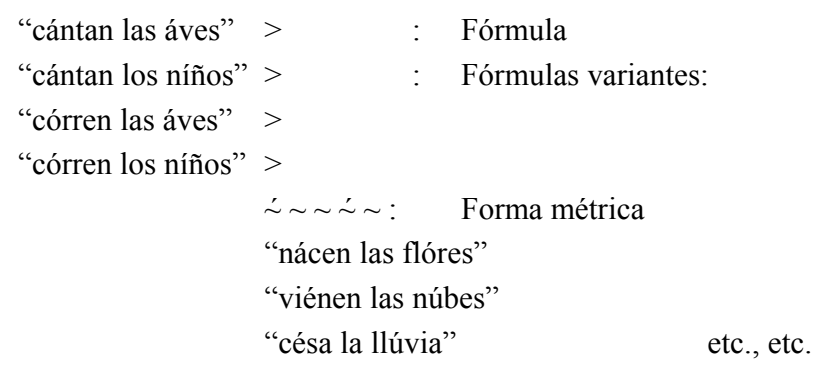

Se trata de unas frases, de unos patrones fraseológicos que por un motivo $\mathrm{u}$ otro se han hecho relevantes y cuya relevancia hace que se los ejecute con una especial atención, con un énfasis especial en lo lingüístico y oral, énfasis que puede incluso expresarse en una especial tensión corporal que se manifieste en una gesticulación concreta y movimiento concreto, es decir, en una especie de danza; puede incluso que unas expresiones de este tipo lleguen incluso a ser acompañadas por unos instrumentos que las apoyen y subrayen. Todos estos factores contribuirían, a su vez, a dar nueva relevancia a dichas frases, que terminarían así fijándose y haciéndose "tradicionales", a la vez que generarían unos patrones rítmico-métricos, los cuales, con su propia dinámica, terminarían regulando la nueva fraseología no tradicional. Fraseología tradicional y forma rítmico-métrica tradicional serían correlativas en su origen, aunque luego cada una evolucionara por su cuenta. En el punto de arranque la "fraseología tradicional" establecería y a la vez regularía los patrones rítmico-métricos por la fuerza de lo precedente; pero, a su vez, estos 
patrones rítmico-métricos fijados evolucionarían dinámicamente por sí mismos y se constituirían en reguladores de la nueva fraseología tradicional que se va introduciendo. Llegando a ser una estructura de pleno derecho, el metro puede así desarrollarse independientemente de la "fraseología tradicional" de donde surgió; es incluso posible que las leyes del metro, una vez desarrolladas, puedan difuminar e incluso borrar aspectos de la verdadera fraseología que originariamente los engendró, si dichos aspectos no hacen juego ya con el metro que se ha establecido ${ }^{11}$.

\subsection{Fase de tradición oral.}

Una vez establecidas unas formas métricas o rítmico-métricas, que conoce y comparte la comunidad lingüística o cultural, podemos empezar a hablar de la existencia de un sistema métrico o rítmico-métrico, distinto de su realización. Se trata de algo aparte del habla normal: un conjunto de formas rítmico-métricas "artificiales", distintas de las unidades rítmicas naturales de dicha habla normal. Se trata, en otro sentido, de unas estructuras formales nuevas, que comparten los miembros de la comunidad lingüístico-cultural como un elemento más de su conciencia colectiva, y que constituyen algo abstracto, disponible para su realización concreta en un momento concreto por uno(s) de los miembros de dicha comunidad.

Estas estructuras formales no hay que concebirlas como algo ya fijado y consolidado, sino in fieri, a caballo, por así decirlo, entre la fórmula, la frase y la auténtica "forma rítmico-métrica" tal como luego la entendemos.

Unidad básica en la estructura rítmica de este primitivo canto o lenguaje versificado es el colon ${ }^{12}$. Tanto en la tradición eolia, como en los dáctilo-epítritos de la doria se trata de unos cola fundamentales relacionados entre sí por catalexis y/o acefalia, con posibilidad de expansión interna coriámbica o dactílica y ampliables o combinables entre sí con o sin ensamblaje ${ }^{13}$. Y estos mismos procedimientos se observan también en la versificación primitiva de

11 Nagy 1974, pp. 196 y 216; 1990, p. 460; Allen 1973, p. 258.

12 Cf. Luque 1999.

13 Por "catalexis" se entiende la abreviación de una unidad rítmico-métrica a base de eliminar la sílaba final y hacer que la penúltima, al convertirse en final, adquiera la posibilidad de breuis in longo, es decir, se convierta en una posición indifferens. - La "acefalia" supone desde una perspectiva sincrónica la eliminación de la primera sílaba de una unidad métrica. - "Ensamblaje" (Dovetailing) se denomina el fenómeno según el cual un corte de palabras al final de una unidad métrica salta una posición adelante y pasa después de la primera sílaba de la unidad siguiente (Nagy 1974, pp. 279 ss.). 
otros pueblos indoeuropeos, de modo que se puede hablar de una mecánica versificatoria común indoeuropea ${ }^{14}$. Especialmente importante parece haber sido un primitivo colon octosilábico indoeuropeo, germen de cola dímetros básicos como el gliconio en la tradición eolia o el prosodíaco en la dáctiloepítrita (los cuales, a su vez, muestran estrecha afinidad con las grandes formas de la tradición jonia, como el hexámetro dactílico, el dístico elegíaco $\mathrm{y}$ el trímetro yámbico). Ambos dímetros griegos, gliconio y prosodíaco, y otros muchos como el dímetro yámbico, o el trocaico, o el coriámbico, o el trocaico-coriámbico o el coriámbico-yámbico ${ }^{15}$, son el resultado de diversas regularizaciones progresivas en sentido retrógrado, es decir, desde la cláusula hacia el comienzo ${ }^{16}$. El griego además, en este sentido, se caracteriza frente al indio por su marcada tendencia a fijar una pluralidad de patrones rítmicos autónomos, en vez de manejar como aquella lengua una estructura rítmica única y versátil, capaz de albergar en su seno múltiples variantes.

Las respectivas variantes de estos dímetros a base de siete o nueve sílabas se entienden sincrónicamente como variantes acéfalas, catalécticas o hipersilábicas. Pero la evidencia comparativa ha demostrado que diacrónicamente no hay que entenderlas como derivadas de los dímetros octosilábicos, sino como herencia paralela junto a ellos. Se trata simplemente o bien de formas independientes de ocho y siete sílabas cuya igualdad rítmica en la cláusula ha dado la impresión de que en el heptasílabo se ha producido la pérdida de la sílaba inicial; o bien de octosílabos y heptasílabos coincidentes rítmicamente en el comienzo y que han sido asimismo interrelacionados a base de la supuesta pérdida de una sílaba final; o bien de octosílabos y eneasílabos cuya igualdad rítmica en la parte inicial los ha relacionado suponiendo la adición de una sílaba al de ocho.

Aquí, aunque se trate de "formas rítmico-métricas" en trance de consolidación, cabe ya distinguir entre "forma métrica" y "forma rítmica", ésta última como nivel más abstracto, del que aquélla es una de las posibilidades, la que la expresa a base de parámetros lingüísticos.

Estas "formas" (rítmicas y métricas) constituyen un rudimentario sistema, susceptible de realización oral; aún no hemos llegado a la fase de realización escrita para la poesía o para la música. En ese sentido, en la realización de este sistema no hay aún distinción entre la "composición" y la "ejecución".

14 Nagy 1990, p. 441.

15 Con sus respectivas variantes acéfalas y/o catalécticas.

16 Watkins 1963, pp. 203 ss.; Nagy, 1974, pp. 30 ss. 
En esta fase de tradición oral podríamos representar estos niveles del siguiente modo:

\begin{tabular}{ll} 
SISTEMA: & $\begin{array}{l}\text { Forma rítmica } \\
\text { Forma métrica }\end{array}$ \\
\hline---------------------------------------- \\
REALIZACIÓN: & Composición-Ejecución
\end{tabular}

Separo el sistema de su realización mediante una línea discontinua para indicar que, sobre todo en las primeras fases, hay que concebirlo como algo aún no consolidado por completo, no del todo independiente de la "composición": en esas primeras etapas de la expresión artística oral todavía funciona a pleno rendimiento la "dicción formular" y cabría reconocer en las "formas" una falta de consolidación como tales.

No distingo entre "composición" y "ejecución" puesto que aún no hemos llegado a la fase del poeta o compositor, cuya obra es ejecutada luego por otro; estaríamos todavía en la fase de los aedos-rapsodas, en la que cada "ejecución" sería a la vez un acto de "composición".

\subsection{El paso a la poesía escrita}

Este paso supondría la distinción entre el plano de la "composición" y el de la "ejecución", aunque tampoco hay que ligar exclusivamente dicho paso a la escritura; la fijación de un texto puede ser fruto también de una tradición oral, en la medida en que una "composición" determinada se fija y se transmite de memoria de un lugar a otro, de una a otra generación.

En cualquier caso, lo fundamental es la fijación, oral o escrita, de un texto, de una "composición", que es respetada por los demás, dando así lugar a una tradición. En ese momento la figura del compositor o poeta queda distinguida de la del recitador o ejecutante. Esto supone en el plano del sistema la consolidación de unas "formas"; supone igualmente el establecimiento de dos niveles claramente diferenciados en la realización del sistema.

Esta nueva situación podríamos representarla del siguiente modo:

\begin{tabular}{ll} 
SISTEMA: & $\begin{array}{l}\text { Forma rítmica } \\
\text { Forma métrica }\end{array}$ \\
\hline & Composición \\
REALIZACIÓN: & $\ldots \ldots \ldots \ldots \ldots \ldots \ldots$ \\
& Ejecución.
\end{tabular}


Ahora hay que suponer unas "formas" más fijas; como he dicho, la tradición (oral y, sobre todo, escrita) contribuye a dicha fijación. Por ello separo con una línea continua el sistema de la realización, las "formas" de la "composición". Represento, en cambio, con un trazo distinto la separación entre "composición" y "ejecución"; considero, en efecto, que la separación entre "formas" y realización no es del todo igual a la que media entre "composición" y "ejecución": ambas tienen en común solamente el pasar de un nivel más general a otro más concreto, pero la "composición" significa dar cuerpo a algo abstracto como es la "forma métrica" a base de materiales lingüísticos concretos (sílabas, palabras, frases); la "ejecución" supone sólo la concreción que en cada momento se lleva a cabo, en forma oral o escrita, de dichos materiales lingüísticos versificados.

Ésta sería, por tanto, la estructura de niveles en una época que podríamos llamar "protoliteraria" e imaginar como "preteórica". "Preteórica" con todo tipo de salvedades y precauciones, pues, si, como acabo de repetir, la escritura debió de contribuir a la fijación de las "formas", no hay que olvidar que esa misma escritura tuvo que entrañar un proceso de racionalización de dichas "formas" y, con ello, un inicio de análisis, de "medida" de las mismas. Análisis y medida que hay que suponer cada vez más necesarios, en tanto en cuanto se vaya asentando la distinción entre compositor y ejecutor.

En una palabra, en este proceso de fijación de las "formas" y de su transmisión desde un compositor a otros ejecutantes hay que reconocer ya en germen un futuro "sistema métrico". Lo cual nos sitúa ya en puertas de una nueva fase.

\section{La etapa teórica.}

Desde el punto y hora en que empiecen a interpretarse y medirse de alguna manera las formas, es decir, desde el momento en que empiece a conformarse un sistema teórico, hay que tener en cuenta un nuevo factor en nuestra estructura de niveles de análisis. En efecto, ya no se parte simplemente de una "forma rítmica", sino de una "forma rítmica racionalizada, interpretada, medida". Lo cual es una precisión que, lejos de ser banal, no se podrá nunca perder de vista: porque en lo sucesivo quienes compongan un poema en dicha "forma" lo hacen conscientes de dicha "medida"; porque, en virtud de ello, dicha "medida" ha podido desde muy pronto condicionar, mediatizar, no ya sólo la "forma rítmica" y la "forma métrica", sino incluso la "composición" y la "ejecución"; porque desde nuestra actual perspectiva, para inter- 
pretar la "forma", puede ser tan necesario el conocimiento de la propia "forma" como el de la(s) medida(s) o interpretación(es) de que fue objeto.

Por todo ello, en adelante hay que hacer entrar esta "medida" en nuestra estructura de "niveles", que habría que concebir así:

\begin{tabular}{ll} 
SISTEMA: & $\begin{array}{l}\text { Forma rítmica } \\
\text { Forma métrica }\end{array}$ \\
\hline & Composición \\
REALIZACIÓN: & $\ldots \ldots \ldots \ldots \ldots \ldots$ \\
& Ejecución.
\end{tabular}

En lo que atañe a este nuevo factor de la "medida", debemos aún hacer varias precisiones, como, por ejemplo, sobre su propia entidad (qué entendemos exactamente por "medida"); sobre su historia; sobre sus aciertos y desaciertos; sobre su relación (condicionante y/o condicionada) con el resto de los niveles.

4.1. Por "medida" entendemos una interpretación, un análisis racional de la "forma rítmico-métrica", es decir, una división y una racionalización.

4.1.1. Supone reconocer en ella un $\lambda$ ó $\gamma$ os, una ratio, una organización:

a) percepción o reconocimiento en cada "forma" de una dimensión determinada;

b) percepción o reconocimiento en el interior de cada "forma" de determinados factores de regularidad, bien unos patrones silábicos fijos en ciertos lugares (los finales, por ejemplo), bien una serie de unidades menores recurrentes que la constituyen y la "miden" (lo cual, a su vez, contribuye a potenciar la regularidad: en efecto, la conciencia de dichos patrones recurrentes propicia la regularidad de los mismos y de su recurrencia). Es lo que debió de ocurrir con los primitivos cola octosilábicos, al irse fijando como dímetros, o con las formaciones más largas surgidas a partir de ellos por expansión interna, dactílica o coriámbica. Es, sobre todo, lo que ocurrió en la versificación jónica, que, frente a la eolia, en cada forma propició un único tipo de intervalo, simple o doble, entre los tiempos marcados, optando así por series regulares bien del

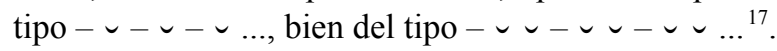

c) percepción o reconocimiento de un $\lambda$ ófos, de un principio de organización interna en dichas unidades menores.

d) reconocimiento de diversos tipos o géneros ( $\gamma \varepsilon \dot{v} \eta \eta)$ en dichas unidades, según dicho $\lambda$ ó yos interno (dactílicos, anapésticos / yámbicos, trocaicos / peónicos).

17 Luque 1995, pp. 258 ss. 


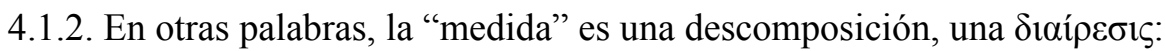

a) de la "forma" en unidades de medida;

b) de dichas unidades de medida en partes: una marcada y otra no marcada, $y$,

c) como consecuencia de ello, la distinción de varias especies ( $\varepsilon$ ¿̌ $\delta \eta)$ dentro de cada género ( $\gamma \varepsilon ́ v o \varsigma)$, según la posición inicial o final de las partes o tiempos marcado (T) y no marcado (t): dactílica / anapéstica; trocaica / yámbica; peónica "primera"/ peónica "cuarta".

4.1.3. Supone incluso esta "medida" en su interpretación racional de las "formas" el reconocimiento de la posibilidad de ruptura de dicha racionali-

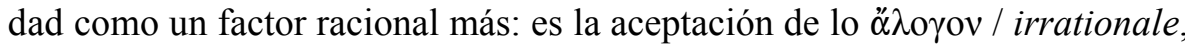
o sea, la convención de la ruptura ocasional del $\lambda$ ó $\gamma o \varsigma$ dominante en unas determinadas "formas".

4.1.4. El establecimiento de la "medida" conlleva importantes implicaciones o consecuencias teóricas como las siguientes:

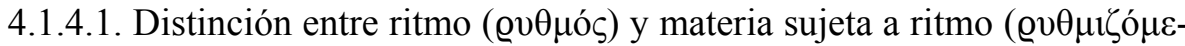
vov).

a) Reconocimiento de aquél como instancia más abstracta y como "forma"

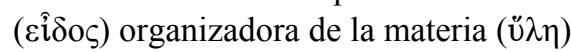

b) Reconocimiento de distintos elementos o factores "ritmables", sometibles a

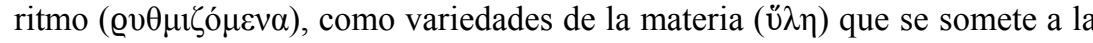

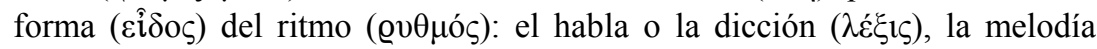

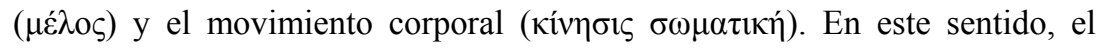
verso ( $\left.\mu \varepsilon^{\prime} \tau \rho o v\right)$, cantado o no cantado (es decir, con o sin $\left.\mu \varepsilon ́ \lambda o \varsigma\right)$ es una

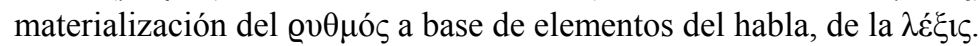

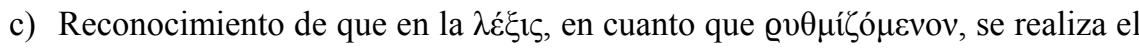

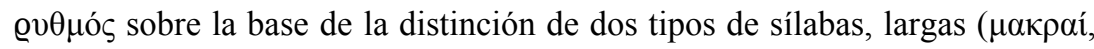
longae) y breves ( $\beta \rho \alpha \chi \varepsilon i ́ \alpha 1$, breves); distinción que, por supuesto, se basa en la realidad prosódica de la lengua.

4.1.4.2. Establecimiento de la convención de que una sílaba larga y dos sílabas breves son intercambiables en lugares convenidos.

Dicha convención es el resultado de un largo proceso que parece haber comenzado por la innovación ${ }^{18}$ de contraer dos breves en una larga $(\varpi)$, una innovación que no haría más que reflejar en el verso fenómenos de la lengua común ${ }^{19}$. Consecuencia de dicha innovación debió de ser su inversa, es decir,

18 Observable en los dáctilo-epítritos de Estesícoro.

19 Como la contracción de vocales consecuente a la caída de fonemas intervocálicos, la 
la resolución de una larga en dos breves $(\simeq)^{20}$. Luego, poco a poco, se habrían reforzado mutuamente ambos fenómenos, desde el punto y hora en que empezaran a ser considerados equivalentes y se distinguiera cada vez menos entre $-\mathrm{y} \simeq$, dando lugar a lo que se ha denominado "river of dactyls" 21 .

4.1.4.3. El reconocimiento de dicha equivalencia y la extensión de dicha convención supone una consolidación de las formas métricas, que asumen autonomía y dinámica propia al margen de las frases de donde surgieron.

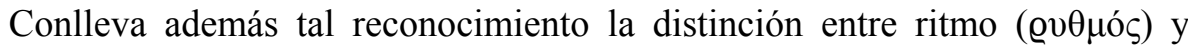

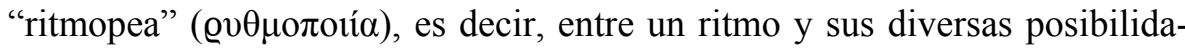
des de manifestarse, entre una "forma rítmico-métrica" unitaria y las diversas concreciones que admite. Dicho en otras palabras, el reconocimiento de que,

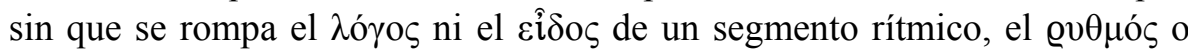
sus unidades se pueden manifestar de distintos modos, pueden adoptar apariencias distintas $\left(\sigma \chi \chi^{\prime} \mu \alpha \tau \alpha\right)$. En virtud de ello, segmentos aparentemente

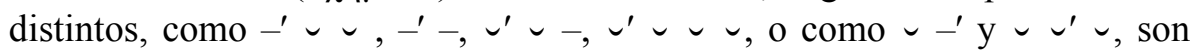
reconocidos como equivalentes, en cuanto que manifestaciones o variantes $(\sigma \chi \eta \dot{\mu} \mu \tau \alpha)$ de una misma unidad rítmica: respectivamente, un compás $\tau \varepsilon \tau \rho \alpha ́ \sigma \eta \mu о \varsigma$ (de magnitud cuatro) con $\lambda o ́ \gamma o \varsigma$ í $\sigma o \varsigma$ y ritmo descendente (T t) o

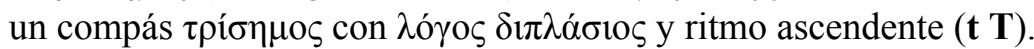

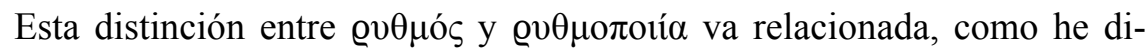
cho, con el reconocimiento de la intercambiabilidad de una sílaba larga y dos breves, aunque también con el de la presencia de variantes "irracionales"

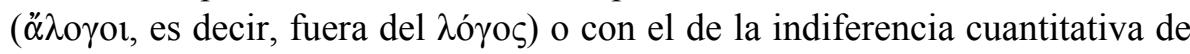
determinados lugares o posiciones, como la final.

Para mí, en esta interpretación de la génesis o establecimiento de la estructura de niveles que me he propuesto, resulta todo esto de una especial relevancia. En efecto, el reconocer que un mismo ritmo, una misma "forma rítmico-métrica", puede manifestarse de distintos modos $(\sigma \chi \eta \mu \alpha \tau \alpha)$ supone la introducción de un nuevo nivel en dicha estructura, el nivel del "esquema", es decir, de las distintas posibilidades de variación convenidas dentro de una misma "forma".

síncopa, etc.: cf. Zirin 1970, pp. 76 ss.; Allen 1973, pp. 60 ss, 163, 255 ss.; West 1982, p. 35; Nagy 1990, pp. 453 ss.

20 Atestiguada también en Estesícoro, aunque limitada en principio a las posiciones en que una larga alternaba libremente con una breve, como, por ejemplo, la inicial del prosodíaco.

21 Haslam 1974, p. 32, citado por Nagy 1990, p. 454. 
Nuestro gráfico ha de ser entonces reelaborado en los siguientes términos:

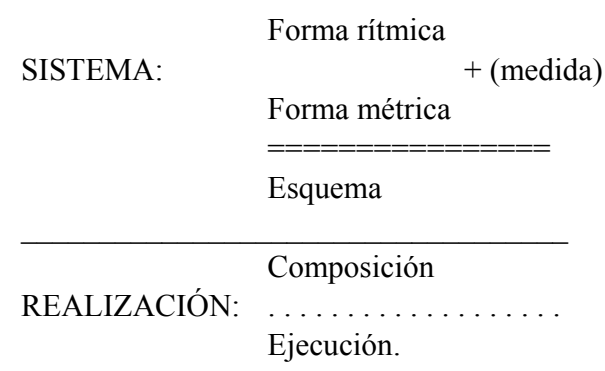

4.1.4.4. Surge asimismo en todo este proceso de "medida" la distinción

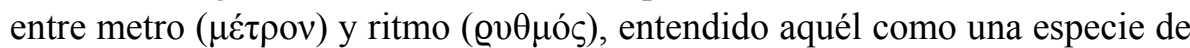
éste: aquél como algo medido, definido, con unos límites; éste como una secuencia indefinida.

4.1.4.5. Supone, como he dicho, la "medida" de las "formas rítmico-métricas" una interpretación racional de las mismas; interpretación que lleva a interrelacionarlas unas con otras y a organizarlas en un sistema lo más coherente posible:

a) Se reconocen así interrelacionadas las "formas" con un mismo $\mu \varepsilon ́ \gamma \varepsilon \theta 0 \varsigma, \lambda o ́ \gamma o \varsigma$

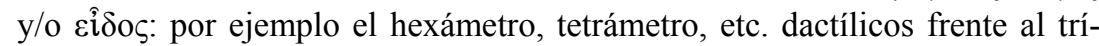
metro, dímetro, etc. yámbicos.

b) Y no sólo esto, sino que se intensifican procesos a los que antes me he referido, como el reconocer como una misma "forma", y reinterpretarlas como variantes sincrónico-funcionales, "formas" que diacrónicamente eran independientes. Tal es el caso de "formas" que terminan interrelacionadas en virtud de la denominada "catalexis" (con sus diversas variantes: catalexis, braquicatalexis, hipercatalexis) $)^{22}$, de la "acefalia", de la "anáclasis"23, etc.

4.1.5. Finalmente la consolidación de esta "medida" con todo lo que entraña de racionalización y sistematización, y con todo el aparato teórico que se

22 Cf., por ejemplo, Parker 1976; West 1982b. En esta reinterpretación a posteriori no dejan de producirse inconsecuencias como la que se observa en diversas variantes cuantitativas del antiguo octosílabo/heptasílabo con sus respectivas cadencias "brusca" y "suave": así, mientras que $\sim-v-\sim-\checkmark \sim$ y $\sim-\checkmark-\sim-\sim$ se han reinterpretado como variantes acataléctica y cataléctica de una misma forma (el "dímetro yámbico"), $\sim \sim-\smile \cup-\smile \sim$ y $\sim \sim-\checkmark \checkmark-\sim$ han seguido siendo entendidas como dos formas independientes (el "gliconio" y el "ferecracio").

23 Se reinterpretaron así como posteriores formas que en realidad eran anteriores, en cuanto que menos regulares: es, por ejemplo, el caso del colon $\checkmark \checkmark-\checkmark-\checkmark--$ reinterpretado como "dímetro jónico a minore ( $\smile--\smile \smile--)$ con anáclasis" (es decir, inversión rítmica), en lugar de ver en él un antecedente aún no regularizado del "dímetro jónico a minore" normal. 
articula en torno a ella, con todo lo que supone de plena conciencia de las formas, tiene una consecuencia práctica casi inevitable: la regularización progresiva de dichas formas métricas "medidas", es decir, racionalmente interpretadas.

4.2. La historia de dicha "medida" resulta para nosotros siempre difícil y tortuosa, conociéndola como la conocemos casi exclusivamente por lo que de ella nos han transmitido fuentes tardías ${ }^{24}$. En tales condiciones dicha dificultad aumenta al tiempo que pretendemos remontarnos hacia atrás y aún más si queremos reconstruir su génesis y sus primeras etapas.

Aunque con diverso sentido en cada momento, hay que pensar siempre en una estrecha relación entre teoría y práctica; de la praxis tuvo que surgir la teoría, la cual, una vez consolidada, se convirtió en un condicionante continuo de aquélla.

Hay que reconocer igualmente un núcleo doctrinal anterior a la escuela propiamente dicha; baste recordar una serie de términos técnicos del tipo de

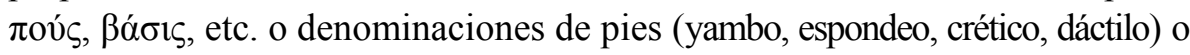
de versos (gliconio, asclepiadeo) que denotan claramente un carácter "preescolar", frente a otros, probablemente posteriores, que traslucen el ambiente

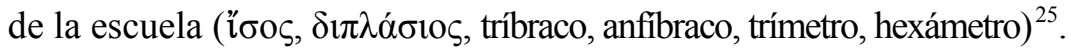

Hay que tener en cuenta, para valorar en sus justos términos la teoría, los avatares por los que fue pasando la propia realidad del verso y las circunstancias, presupuestos, perspectivas, etc. con que se llevó a cabo en cada momento su análisis o interpretación teórica. No es lo mismo en este sentido la

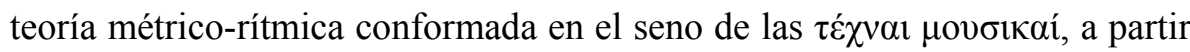
de la observación y la experiencia directa de una ejecución "musical" de las mismas, que las doctrinas métricas que, sobre la herencia de dicha antigua rítmica musical, se consolidan luego en manos de los filólogos alejandrinos, que, con unos intereses y una óptica distinta, estudian quizá las mismas formas, pero ya sólo en su realización escrita, sin tener además el referente directo de su antigua ejecución ${ }^{26}$.

Y además de todo lo dicho, no hay que olvidar la enorme fuerza de la tra-

\footnotetext{
24 Sobre la problemática general de las antiguas doctrinas rítmico-métricas, $c f$. Luque 1987, pp. 15 ss.

25 De todo ello me he ocupado en ocasiones anteriores: Luque 1986; 1994, pp. 13 ss.; 1995, pp. 239 ss.;

26 Luque 1987, pp. 9 ss.
} 
dición en la transmisión de estas doctrinas de maestros a discípulos, de modo que dicho corpus doctrinal hay que concebirlo como una corriente que fluye sin cesar, recibiendo la herencia establecida e incorporando a la vez a su caudal las nuevas aportaciones y perspectivas, las cuales en ocasiones se mezclan a lo anterior indiscriminadamente, dando lugar a todo tipo de desfases, anacronismos, inconsecuencias y malentendidos.

Una cosa es lo que supone para la medida una primera "fase orquéstrica", en la que la propia gesticulación y danza, unida a un acompañamiento instrumental más o menos complejo, es la que ha potenciado las primitivas fórmulas contribuyendo a su fijación en unas formas rítmico-métricas fijas y a la vez ha puesto las bases para que se tomara conciencia de la "medida" de dichas formas.

Otra cosa es la consolidación de toda esta medida e interpretación de unas formas ya más o menos establecidas en una "fase musical", en la que dichas

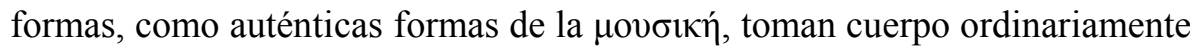

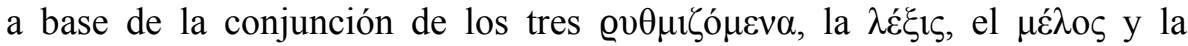

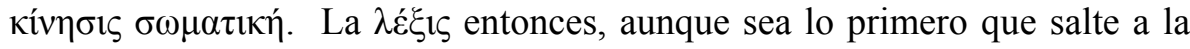
vista de quien analiza aquellas formas, aparece siempre reforzada por los otros dos componentes.

Otra cosa es la interpretación de dichas formas cuando ya la $\lambda \varepsilon \dot{\varepsilon} \xi 1 \varsigma$ se ha ido desligando del $\mu$ É $\lambda$ $\varsigma$ y del movimiento corporal y se trata de unos versos recitados, no cantados. En esta fase "métrica" las formas se hallan más expuestas al peso y a la presión del lenguaje, puesto que ya no tienen el refuerzo de la música o de la danza.

Otra cosa, finalmente, es la interpretación de dichas formas, con otros intereses y perspectivas, los del lenguaje escrito, al margen no ya sólo de su musicalidad original, sino incluso de su oralidad.

Por no hablar de la "medida" ya consolidada y transmitida de generación en generación e incluso trasvasada, junto con las formas, a otra lengua y a otra cultura; o de los avatares de las formas y de su medida cuando con el tiempo cambia incluso la base lingüística que las había sustentado.

Sin ir más lejos, en el propio principio de medida y en la unidad básica de dicha medida, el pie o compás, se pueden apreciar distintas etapas ${ }^{27}$, cada una de las cuales ha ido dejando en este caudal de la doctrina rítmico-métrica sus propios principios y terminología: una etapa "orquéstrica" en que la me-

27 Luque 1994, pp. 104 ss.; 1995, pp. 12 ss. 
dida es el paso de danza, el pie; una etapa "poético-musical" en que la música (y el ritmo, en consecuencia) se halla íntimamente ligada a la dicción $(\lambda \dot{\varepsilon} \xi 1 \varsigma)$, lo cual lleva a medirlo por sílabas, y a concebir el pie como una entidad lingüístico-musical; una fase "rítmica", que se inicia con Aristóxeno, cuando se aisla el ritmo como instancia abstracta por encima de los materiales sometidos a él, se lo concibe como "ordenación del tiempo" y se

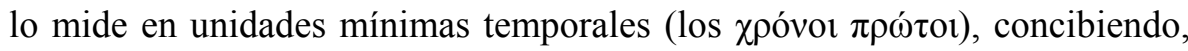
en consecuencia, el pie como una entidad o magnitud rítmico-temporal; y finalmente una fase "métrica" en que, olvidados progresivamente los principios de la rítmica y reducida cada vez más la teoría métrica a la descripción de los versos escritos desde la óptica de la gramática, se vuelve de nuevo a la sílaba, considerando el pie como un mero patrón silábico, más o menos anquilosado y sin sentido rítmico.

No hay que olvidar tampoco las dos corrientes que se aprecian en época helenística en la configuración de la teoría métrica, los dos sistemas métricos, como se los suele denominar, el "alejandrino" y el "pergameno", aunque, de suyo, el auténtico sistema sea propiamente el primero. Ambos, con independencia de la cuestión largamente debatida de la prioridad temporal de uno u otro y por encima de sus concomitancias, suponen dos grados distintos de proximidad o, mejor, de alejamiento respecto de las doctrinas rítmicas de donde partieron ${ }^{28}$.

4.3. Los desfases, inconsecuencias e irregularidades que ha supuesto para la teoría métrica toda esta trayectoria saltan a la vista. A los malentendidos, confusiones e incluso errores que entrañó el paso de la doctrina rítmica a la doctrina métrica y el alejamiento progresivo de ésta última, como disciplina filológica, respecto de la rítmica musical de donde tomó origen ya me referí en otra ocasión ${ }^{29}$ : trajo, por ejemplo, consigo este alejamiento confusiones entre "formas" y "esquemas", no distinguiendo debidamente entre auténticos pies o compases de verdadera entidad rítmica y variantes accidentales ("esquemas") de dichos pies; tal, por ejemplo, el caso del reconocimiento del denominado "pirriquio", que tanto condicionó la posterior interpretación y clasificación de los pies métricos ${ }^{30}$. Trajo asimismo confusiones entre la can-

\footnotetext{
28 Luque 1995, pp. 327 ss. y bibliografía allí mencionada, en especial los estudios de Leo y Leonhardt

29 Luque 1995, pp. 52 ss.

30 Por ejemplo, la interpretación de los pies "jónicos" no como pies simples del $\gamma \varepsilon \dot{v} v \varsigma_{\zeta} \delta$ -

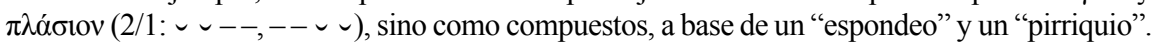




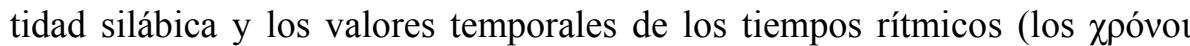

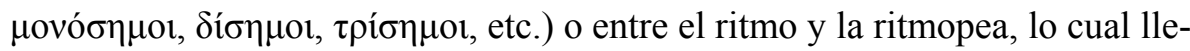
vó a hablar, con un criterio meramente visual o gráfico (la posición de la síla-

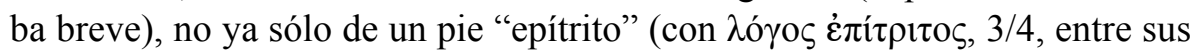
dos tiempos: $-\smile \mid--)$, sino de cuatro: uno "primero" ( ----$)$, otro "segundo" (- --$)$ otro "tercero" (- --$)$ y otro "cuarto" (- - $-\checkmark)$; algo similar a lo que ocurrió con la adición de dos peones más (el "segundo" $\checkmark-\smile \smile$ y el

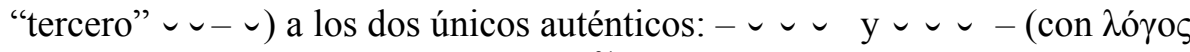
$\dot{\eta} \mu \iota^{\prime} \lambda 10 \varsigma, 2 / 3$ o 3/2, entre sus tiempos) $)^{31}$.

Desajustes por el estilo trajo consigo a la "medida", a la doctrina métrica, la evolución histórica de la propia poesía o versificación, por ejemplo, el paso desde una poesía cantada a otra recitada, mientras que la rutina escolar o la fidelidad a la tradición mantenían en la teoría los principios de antes, sin adaptarlos a la nueva realidad: seguían así en vigor, más o menos anquilosados, conceptos y términos propios del canto o de la música en una doctrina que ya se proponía "medir", ante todo y sobre todo, versos hablados; de ahí, por ejemplo, la pervivencia de principios musicales, como el de la isocronía de las unidades (las sílabas, los pies, etc.), en un medio como el lenguaje, ajeno en buena medida a ellos.

Este mismo desfase entre la práctica y la teoría, entre el "verso" y su "medida" tiene lugar, ahora en sentido inverso, cuando en la práctica filológica o en la enseñanza escolar se analizan y "miden" con criterios de la época unos textos que conservan formas versuales que corresponden a realidades muy distintas, propias de la poesía o de la música de tres, cuatro o cinco siglos antes.

El anquilosamiento de una "medida" rutinaria, escolar, desconectada casi por completo de la realidad fónica, rítmica, de los versos que mide, da como frutos conceptos y términos como los de "pentámetro dactílico" ${ }^{32}$, para definir un período de dos cola "hemíepe" de dos pies y medio cada uno, o los de "septenario", para denominar versos que, de suyo, son octonarios catalécticos. Términos como éstos ponen de manifiesto, como digo, el distanciamiento que de la forma rítmico-métrica puede alcanzar la "medida".

Un distanciamiento similar da a entender el hecho de que, en aras de un sistematismo a ultranza, unos versos como los eólicos, de naturaleza silá-

31 Son los dos únicos que reconocen, por ejemplo, Aristóteles o Cicerón.

32 Cf. Luque 1994b, pp. 9 ss. 
bico-cuantitativa, se interpreten con frecuencia a lo largo de toda la historia de la métrica como si fueran versos cuantitativos, de pies, del tipo de los yámbicos, dactílicos, etc. de la versificación jonia.

No menos desaciertos ha traído consigo en la historia de la métrica una insuficiente distinción de niveles: es lo que ocurre, por ejemplo, cuando no se distingue debidamente entre "cesura", algo propio de la "composición", y "juntura", algo que, como ocurre en el pentámetro, pertenece a la "forma". No es ajena dicha confusión a problemas tan sangrantes como el del papel del acento en la versificación latina (en época clásica nunca pertinente en el nivel de la "forma", pero sí importante en el plano de la "composición") o el denominado "problema del ictus"; de tantos quebraderos de cabeza como ha producido esta cuestión se habrían evitado muchos si se hubiera distinguido correctamente entre la "marca rítmica", algo propio de la "forma rítmicométrica", y cualquier golpe (ictus), vocálico o mecánico, que trata de reproducirla en el momento de la "ejecución"33.

4.4. La "medida", en cuanto que interpretación de la "forma rítmico-métrica", va, por naturaleza, referida, ante todo y sobre todo, a ella; en este sentido, el proceso de definición de las "formas versuales" se identifica por lo general con el proceso de establecimiento de una determinada "medida": no otra cosa ocurrió, por ejemplo, con la consolidación a partir del primitivo octosílabo indoeuropeo de "formas" como el gliconio, el dímetro yámbico, el dímetro trocaico, etc; cada una de ellas corresponde a una peculiar regularización de dicho octosílabo, lo cual, en último término, se identifica con una determinada "medida" de aquella originaria unidad isosilábica. Y otro tanto, mutatis mutandis, cabe decir en la constitución de otras muchas "formas", como las de los períodos largos, a partir de otros más cortos, a base de adiciones, extensiones o expansiones internas.

Pero la íntima relación que guardan entre sí "forma" y "medida" no quiere decir que ésta última no mantenga relación también, más o menos estrecha, con los demás niveles de funcionamiento del lenguaje versificado.

Los "esquemas", por ejemplo, reflejan directamente la "medida" que se hace de cada "forma". Piénsese, por ejemplo, en la tendencia a la claridad y pureza rítmica de las cadencias, de los pies finales en los períodos jónicos o de las sílabas últimas de los versos eólicos. Recuérdense asimismo las diferencias que supone en las variantes "esquemáticas" de una "forma" el

33 Cf. Luque 1994, pp. 27 ss. 
hecho de que dicha "forma" se mida por pies (versos dactílicos) o por dipodias (versos yambo-trocaicos y, en parte, anapésticos).

Y no sólo en estos niveles del sistema se deja sentir la "medida", la interpretación que se hace de cada "forma"; también la realización de dicho sistema se hace eco en múltiples aspectos de dicha "medida". Basta tener en cuenta, por ejemplo, las diferencias en la "composición" (fraseología, tipología verbal, cantidad fija o indiferente de las sílabas finales, etc.) de determinados versos eólicos según se entiendan, se "midan", como cola (como miembros, de una unidad métrica superior, la estrofa, que actúa como verdadero período métrico) o como períodos autónomos, tanto si, en este caso, siguen integrados en la unidad estrófica como si se independizan del todo y pasan, como pasó el falecio, a un uso estíquico.

Otro tanto cabe decir de las cesuras, diéresis, zeugmas, etc. consagrados en la norma de "composición" de períodos como el hexámetro o el trímetro yámbico; no es descabellado pensar que en un sentido histórico o genético tales fenómenos responden al proceso de configuración (de "medida") de dicha "forma" métrica a partir de otras unidades menores, que muchos de esos cortes articulatorios son la herencia de las soldaduras que estructuraron la "forma" en cuestión, que las que llegaron a quedar como cesuras empezaron siendo "junturas". Tenemos incluso posibilidad de comprobar este proceso en los octonarios y septenarios del teatro romano republicano, que en su "composición" reflejan los dos estados de consolidación como tales períodos $\mathrm{y}$, en último término, las dos "medidas": como dos cola o incluso períodos unidos por una "juntura" o, ya en un estadio más avanzado, como un período único con sus dos cola, ya fundidos y perfectamente ensamblados, separados por una simple cesura. La propia "composición" de estos versos o del senario yámbico en este teatro republicano se hace eco en múltiples aspectos (sobre todo en la tipología verbal o en la relación acento-tiempo marcado) de la "medida" que de ellos tiene presente el versificador: una medida que, aunque monopódica, no deja de recordar la antigua dipódica del teatro trágico griego.

Y, ya más adelante, ¿cómo olvidar, por ejemplo, la posible influencia de la "medida" en la fijación de determinadas normas en la "composición" de versos como los eólicos, en la cual se llegaron a establecer unos cortes fijos y a anquilosarse unos cola que terminaron condicionando la propia evolución acentual de dichos versos o la creación de versos nuevos a base de los denominados cola libera, de acuerdo con los principios de la denominada procreatio metrorum? 
Hasta en la "ejecución" de los versos se deja evidentemente sentir la fuerza de la "medida". Es lo que podemos comprobar en la Antigüedad tardía y en épocas posteriores, cuando, perdido ya el sentido de la cantidad silábica, los recitadores y, sobre todo, los maestros en la escuela pretenden comunicar y poner de relieve la "medida" de los versos a base de una ejecución artificiosa que trata de remedar la antigua pronunciación a base de acentuar los tiempos marcados; esto que ya lo hacía el gramático Sacerdote a finales del siglo III es lo que luego se ha seguido haciendo y se hace aún en la recitación de los antiguos versos ${ }^{34}$.

\section{BIBLIOGRAFÍA MENCIONADA}

Abercrombie, D., 1965: «A phoneticien's view of verse structure», en Studies in Phonetics \& Linguistics, London, pp. 16-25.

Allen, W.S., 1973: Accent and Rhythm. Prosodic Features of Latin and Greek: A Study in Theory and Reconstruction, Cambridge.

Ben-Amos, D., 1976: «Analytical Categories and Ethnic Genres», en Folklore Genres, Austin, pp. 215242.

Cole, A.T., 1969: «The Saturnian Verse», Yale Classical Studies 21, 1969, pp. 3-73.

De Groot, A.W., 1968, «Phonetics in its relation to aesthetics», en B. Malmberg, Manual of Phoneticst, Amsterdam, 1968, pp. 533-549.

Gentili, B., 1950: Metrica greca arcaica, Messina-Florencia.

Gentili, B., 1952: La metrica dei greci, Messina-Florencia.

Hainsworth, J.B., 1964: «Structure and Content in Epic Formulae: The Question of the Unique Expression», Classical Quarterly $58=14 / 2$ n.s., 1964, pp. 155-164.

Haslam, M., 1974: «Stesichorean Metre», Quaderni Urbinati 17, 1974, pp. 7-57.

Jakobson, R., 1952: «Slavic Epic Verse: Studies in Comparative Metrics», Oxford Slavonic Papers 3, 1952, pp. 21-26 = 1966, pp. 414-463.

Jakobson, R., 1966: Selected Writings IV, The Hague.

Jeep, L., 1893: Zur Geschichte der Lehre von den Redetheilen bei den lateinischen Grammatiken, Leipzig.

Lasso de la Vega, J.S., 1961: «Orígenes de la versificación griega», Estudios Clásicos 6, 1961, pp. 140 164.

Leo, Fr., 1899: «Die beiden metrischen Systeme des Altertums», Hermes 34, 1889, pp. 280-301

Leonhardt, J., 1989: «Die beiden metrischen Systeme des Altertums», Hermes 117, 1989, pp. 43-62.

Luque Moreno, J. 1984: «Niveles de análisis en el lenguaje versificado», Athlon, Satura grammatica in honorem F.R.Adrados, vol. I, Madrid, pp. 287-299.

Luque Moreno, J. 1984b: «Sistema y realización en la métrica: bases antiguas de una doctrina moderna», Emerita 52, 1984, pp. 33-50.

34 Mis colegas y amigos, Francisco Fuentes, Pedro Pablo Fuentes y Carmen Hoces han tenido a bien leer el original de este trabajo, que resulta así deudor de sus consejos y observaciones. 
Luque Moreno, J. 1986: «La denominación de los versos en la métrica greco-romana», Estudios Clásicos XXVIII 90, 1986, pp. 47-65.

Luque Moreno, J., 1987: Scriptores Latini de re metrica, Vol. I: Presentación, Granada.

Luque Moreno, J. 1988: «Problemática de las fuentes antiguas de doctrina métrica», Actas del II Congreso Andaluz de Estudios Clásicos (Antequera-Málaga, 1984), Vol. I, Málaga, pp.13-39.

Luque Moreno, J. 1994: Arsis, thesis, ictus, Granada.

Luque Moreno, J., 1994,b: El dístico elegíaco, Madrid.

Luque Moreno, J. 1995: De pedibus, de metris, Granada.

Luque Moreno, J., 1998: «Vox (sonus), sermo, carmen, cantus, versus, oratio», en B. García Hernández (ed.), Estudios de lingüistica latina, Madrid, pp. 971-985,

Luque Moreno, J., 1999: «Caesura-colon-melos-carmen», en J. Luque-P.R. Díaz (eds.) Estudios de métrica latina, vol. II, Granada, pp. 519-538.

Meillet, A., 1923: Les origines indo-européennes des mètres grecs, Paris.

Nagler, M.N., 1967: «Towards a Generative View of the Oral Formula», Transactions and Proceedins of the American Philological Association 98, 1967, pp. 269-311.

Nagy, G., 1974: Comparative Studies in Greek and Indic Meter, Cambridge, Mass.

Nagy, G., 1990: Pindar's Homer. The Lyric Possession of an Epic Past, Baltimore-London.

Nettl, B., 1956: Music in Primitive Culture, Cambridge, Mass.

Parker, L.P.E., 1976: “Catalexis”, Class. Quart. 26, 1976, pp. 14-28.

Parry, A. (ed., trad.), 1971: The Making of Homeric Verse: The Collected Papers of Milman Parry, Oxford.

Parry, M., 1928: L'épithète traditionnelle dans Homère, Paris.

Parry,M., 1928b: Les formules et la métrique d'Homère, Paris.

Pighi, J.B., 1964: «Lineamenti di metrica storica delle lingue indo-europee», Rendic. Accad. delle Scienze dell'Istituto di Bologna, cl. Scienze Morali 53 (1964-65), 25-88 = 1970, pp. 3-65.

Pighi, J.B., 1970: Studi di ritmica e metrica, Turín.

Russo, J.A., 1966: «The Structural Formula in Homeric Verse», Yale Classical Studies 20, 1966, pp. $217-$ 240.

Schönberg, A., 1922: Harmonienlehre, trad. R. Barce, Madrid,1974.

Usener, H., 1887: Altgriechischer Versbau, Bonn.

Watkins, C., 1963: «Indo-European Metrics and Archaic Irish Verse», Celtica 6, 1963, pp. 194-249.

West, M.L., 1973: «Indo-European Metre», Glotta 51, 1973, pp. 161-187.

West, M.L., 1973b: «Greek Poetry 2000-700 B.C.», Classical Quarterly 23, 1973, pp. 179-192.

West, M.L., 1982: Greek Metre, Oxford.

West, M.L., 1982b: “Three Topics in Greek Metre”, Class. Quart. 32, 1982, pp. 281-297.

Wilamowitz, U.v., 1921: Griechische Verskunst, Berlin (=1962)

Zirin, R.A., 1970: The Phonological Basis of Latin Prosody, The Hague. 